\title{
Monitoring of Kilum-Ijim forest bird communities: initial findings
}

\author{
PHILIP F. FORBOSEH, ERNEST C. KEMING, CLEMENT L. TOH and \\ INNOCENT N. B. WULTOF
}

\begin{abstract}
Summary
The Kilum-Ijim forest is an excellent example of the ornithological riches of the Cameroon montane forest biome. The forest is also important to over 200,000 people who exert enormous pressure on the ecosystem. In 1995, the Kilum-Ijim Forest Project began systematic monitoring of birds, with the intention of using them as indicators of the overall condition of the forest, as well as monitoring the status of individual species. Analyses of data collected in 1999-2000 demonstrated some clear differences in habitat use, suggesting suites of bird species may be indicators of changes in vegetation. However, beyond this, little is known about the response of birds to habitat modifications, or the relationship between bird abundance and diversity of other organisms at Kilum-Ijim. It is argued that the objective of assessing changes in vegetation could be more satisfactorily pursued through direct measurement of structural changes in habitats. We highlight the necessity for a shift in the programme objectives to place greater emphasis on monitoring endemic and threatened bird species for their own status and on assessing changes in the bird community as a function of changes in the vegetation.
\end{abstract}

\section{Introduction}

The Kilum-Ijim forest is an excellent example of the ornithological riches of the Cameroon montane forest biome. The site is included in the Important Bird Area (IBA) programme of BirdLife International, which lists 14 Species of Restricted Range, including six Species of Conservation Concern for the area (BirdLife International 2000, Stattersfield et al. 1998). The Biome Restricted Assemblage of the Afrotropical Highlands (Fishpool 1997) lists 43 birds for Cameroon, of which 31 species have been recorded in the Kilum-Ijim forest. Of these, two are endemic to the Bamenda Highlands: Bannerman's Turaco Tauraco bannermani and Banded Wattle-Eye Platysteira laticincta, for which the Kilum-Ijim forest is arguably the last stronghold (Forboseh and Ikfuingei 2001, Collar et al. 1994). IBAs are sites of global biodiversity conservation importance, chosen using internationally agreed, objective, quantitative and scientifically defensible criteria (Bennun 2002).

Over 200,000 people depend on the Kilum-Ijim forest for food, water, firewood, medicines, meat and increasingly, income from tourism. The most serious anthropogenic influences are fire and the use of forest for grazing domestic animals, especially goats, which browse on regenerating trees. As a result, the forest has lost its mega-fauna, including notable species such as leopards, elephants, buffaloes and antelopes. Remaining large mammal populations are 
severely depressed and close to regional extinction. The long-term effects of these extinctions on ecosystem stability and forest regeneration are uncertain.

In 1995, the Kilum-Ijim Forest Project of BirdLife International began systematic monitoring of birds in the area. The intention was to use birds as indicators of the overall health and biodiversity of the forest, as well as monitor their own status. There were three detailed objectives:

- the identification of indicator species (i.e. indicators of mature montane forest and indicators of degraded forest habitats);

- the detection of trends in those indicators that would help in identifying changes in vegetation

- to gain a better understanding of the ecological requirements of the endemic forest birds

The link between monitoring and management follows clearly defined communication strategies that include dissemination of custom written reports and regular meetings with all stakeholders.

A large database was compiled from the initial years of bird monitoring (1995, 1996 and 1997), using standard line transect recording (Bibby et al. 1992). A recent review of the bird-monitoring programme highlighted many shortcomings with the design, including unrepresentative sample areas, and the programme was subsequently revised. Since 1999-2000, bird monitoring has used the revised system. This paper discusses results for 1999-2000, and density estimates are presented for many species for the first time. The sensitivity of the monitoring programme to changes in bird density at a range of sampling effort levels is also assessed. Finally, we comment on the suitability of birds for monitoring forest condition and biodiversity.

\section{Study area and methods}

The Kilum-Ijim forest lies between $6^{\circ} \mathrm{O}^{\prime}$ and $6^{\circ} 20^{\prime} \mathrm{N}$ and $10^{\circ} 20^{\prime}$ and $10^{\circ} 34^{\prime} \mathrm{E}$, in the Bamenda Highlands of north-western Cameroon (Figure 1). The forest spans an altitudinal range from $1,600 \mathrm{~m}$ to $3,011 \mathrm{~m}$, although most of it occurs above $2,000 \mathrm{~m}$. The total area enclosed by the forest boundaries is $c .17,323 \mathrm{ha}$, around half of which is montane forest and the rest montane grasslands, various types of scrubland, and a small area of afro-subalpine grassland at the summit. There is a long wet season and short dry season, with an average of $2,427 \mathrm{~mm}$ of rain falling annually at Kilum and 2,242 $\mathrm{mm}$ at Ijim (Forboseh and Ikfuingei 2001). The rains often start after mid-March and continue until November, with a strong peak in July-August, and sometimes in September. The months of December, January and February have little or no rain. Temperature ranges between $10^{\circ} \mathrm{C}$ and $25^{-2}-8^{\circ} \mathrm{C}$, and the widest range between the 24-hour maximum and minimum occurs between November and March.

Letouzey (1985), Thomas (1986, 1987), ENGREF (1987), Tame and Asonganyi (1995) and Cheek et al. (2000) provide detailed data on the forest vegetation. Maisels and Forboseh (1997) classified the forest vegetation into 11 types, three of which are subsumed into others (Tame and Asonganyi 1995, ENGREF 1987). Table 1 shows the preliminary assessment of the recent distribution of vegetation types based on the Landsat ETM image of 5 February 2001. 


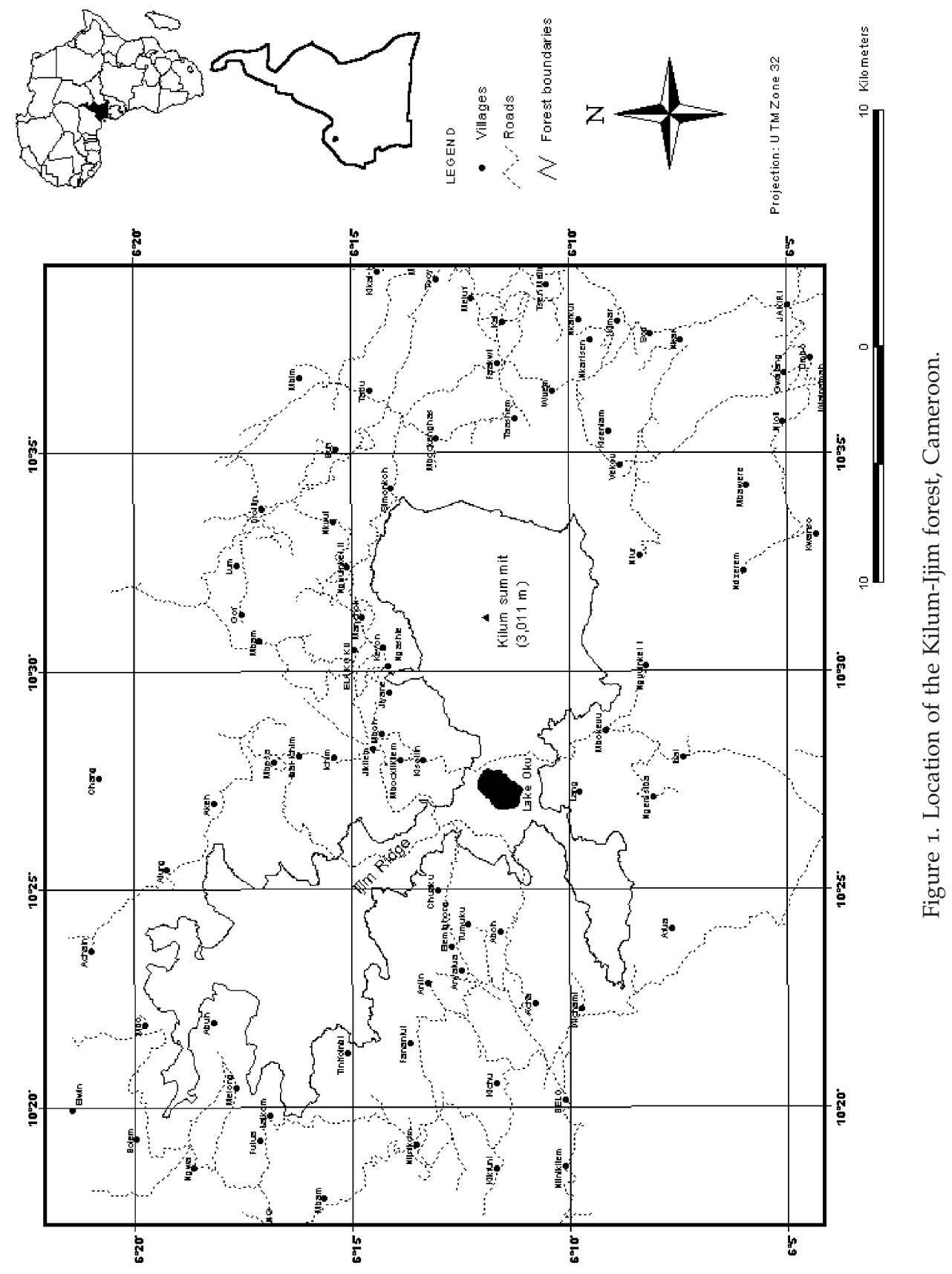


Table 1. The Kilum-Ijim forest vegetation types.

\begin{tabular}{llcll}
\hline $\begin{array}{l}\text { Vegetation } \\
\text { type }\end{array}$ & Class name & Extent (ha) & $\begin{array}{l}\text { Samples } \\
\text { (bird count } \\
\text { stations) }\end{array}$ & $\begin{array}{l}\text { Sampling effort } \\
\text { (number of } \\
\text { surveys) }\end{array}$ \\
\hline 1 & & 153 & 17 & 50 \\
2 & High altitude Podocarpus forest & 1,557 & 28 & 79 \\
3 & Upper altitude montane forest & 5,742 & 29 & 80 \\
4 & Lower altitude montane forest & 1,866 & 21 & 58 \\
& Woodland with Gnidia glauca, Maesa & & & \\
5 & lanceolata & 745 & 29 & 84 \\
6 & Mature bamboo forest & 2,336 & 27 & 68 \\
& Scrubland dominated by Erica & & & \\
7 & (Phillipia) mannii & 4,303 & 19 & 23 \\
8 & Montane grassland up to 2,800 m & 147 & 23 & 26 \\
\hline
\end{tabular}

\section{Data collection}

Two teams, one at Ijim and the other at Kilum, carried out bird counts using the point-count method (Bibby et al. 1992, Buckland et al. 1993). A team comprised an observer, who identified the species and estimated observer-bird distances, and a recorder, who recorded the data onto paper. In order to facilitate examinations of various relationships between bird and vegetation, bird census stations were located at the corner of vegetation monitoring quadrats, each of which was marked with a $1.3 \mathrm{~m}$ metal rod. The rods were painted white and buried $0.3 \mathrm{~m}$ into the ground. Monitoring teams used a GPS to relocate the census stations. There were $14-20$ randomly located plots within each vegetation type, each plot measuring $20 \times 20 \mathrm{~m}$, at least $200 \mathrm{~m}$ apart. In order to increase the precision of bird density estimates, additional bird census stations were randomly located within each vegetation type.

During counting, observers recorded all birds seen or heard within a radius of $200 \mathrm{~m}$, together with their visually estimated distance from the point. Observers received training and had much experience of visual distance estimation. For flocks, the number in the group was recorded. Birds flying over the point were not recorded to minimize the possibilities of double counting highly mobile species. Where birds were seen the age, sex and height in the tree were recorded where possible. During a typical field day, a team would visit 1-4 census stations (subject to weather conditions and distance between stations), but would ensure that counts were conducted between o7hoo and 11hoo. Counts lasted for $30 \mathrm{~min}$ per visit at each point, divided into four periods. During the first period ( $5 \mathrm{~min}$ ), the observers counted all Bannerman's Turacos detected but allowed other birds to settle from any disturbance caused by their arrival. In the second period (10 min) all birds were recorded (including Bannerman's Turacos). During the third period $(5 \mathrm{~min})$ the team recorded only Bannerman's Turacos and species not detected in the previous $10 \mathrm{~min}$. In the fourth period (10 $\mathrm{min}$ ), the observers continued to count only Bannerman's Turacos. The species calls intermittently and the duration between calls can be as long as $30 \mathrm{~min}$, hence the need to count for a much longer period. Thus, the point-count protocol involved a 30-min count for Bannerman's Turaco. Within the 30 minutes is nested a conventional point- 
count for other species, with a 5-min settling-down period, a 10-min count and a 5-min add-on aimed at improving the possibility of recording rare or difficult species.

Bird census stations were visited at most three times a year. The order of plot visits was reversed during the second and third counts in order to minimize systematic bias relating to the timing of counting in different habitats. The first visit was made between July and October 1999 and the second and third visits were made between December 1999 and August 2000. Counting in future years will take place from October to November and from March to June. These periods correspond with the breeding period of most species in the Kilum-Ijim forest (Fotso and Parrot 1991). Sampling effort was highest in forest habitats and lowest in grassland (Table 1). After the first round of bird counts we decided to suspend counting in grasslands and prairies to focus on the forest proper. Should there be major changes in those habitats in the future (e.g. succession by forest), bird counting will resume.

\section{Trend detection: analytical framework}

The Kilum-Ijim Forest Project bird monitoring programme, like others, is based on the ability to detect changes in bird abundance. The issue of change detection revolves around two fundamental questions. First, given two consecutive surveys of a species in one habitat, how small a change in density could we detect at some specified probability level? Second, if there were some statistically significant changes, could they be explained in terms of certain covariates, e.g. human impacts and forest structure? These questions have important implications for the design of the monitoring programme. Fundamentally, their answers will dictate the effort required by the programme. In this section, we propose an analytical framework for addressing the first question. The second question will be addressed subsequently by including information from vegetation plots.

Suppose we conduct a survey of a bird species (i) in one habitat (j) at time $t$ and obtain the mean density (or abundance) as $D_{i j t}$. The question is how small a change in density we could detect in the next consecutive survey. Let $D_{i j(t+1)}$ be the mean density obtained from the next consecutive survey. The test is based on the fact that the quantity

$$
z=\frac{D_{i j t}-D_{i j(t+1)}}{\sqrt{s e\left(D_{i j t}\right)^{2}+\operatorname{SE}\left(D_{i j(t+1)}\right)^{2}}}
$$

is approximately normally distributed (Buckland et al. 1993). If the two surveys employed the same amount of sampling effort, then the standard errors $\operatorname{SE}\left(D_{\mathrm{ijt}}\right)$ and $\operatorname{SE}\left(D_{i j t+1}\right)$ should be approximately equal. Following Walsh and White (1999), let $\Delta D_{i j i t}$ represent the change in mean density since the first survey, where $\Delta$ is the percentage change. Then the density estimate from the second survey can be written as $D_{i j}(t+1)=(1+\Delta) D_{i j t}$ so that

$$
\Delta=\frac{\sqrt{2 Z}_{\alpha} / \operatorname{SE}\left(D_{i j t}\right)}{D_{i j t}}
$$


where $z_{\propto}$ is the $(1-\propto) \%$ critical value from the standard normal distribution. Hence, $\Delta$ is the percentage change in density that can be detected with $(1-\propto) \%$ confidence. Alternatively,

$$
\Delta=\sqrt{2 Z}_{\alpha} C V\left(D_{i j t}\right)
$$

where $\operatorname{CV}\left(D_{\mathrm{ijt}}\right)$ is the coefficient of variation of density. Hence the smaller the coefficient of variation of density the smaller the detectable change. Given a pilot survey with sampling effort $T_{\mathrm{p}}$, the coefficient of variation of a future survey with sampling effort $T$, adapted from Walsh and White (1999), is

$$
C V\left(D_{i j t}\right)=\sqrt{\frac{b T_{p}}{\mathrm{n}_{i j t} T}}
$$

where $n_{\mathrm{ijt}}$ is the number of observations of species $i$ in habitat $j$ during the pilot survey and b as in Walsh and White (1999) and Buckland et al. (1993, p.91). The above model shows that the higher the number of observations in the pilot survey, the smaller the coefficient of variation and hence the larger the power of the monitoring programme to detect real changes in densities.

\section{Data analysis}

For species with sufficient registrations for density estimations, the computations were carried out in DISTANCE (Laake et al. 1993). Distances greater than $80 \mathrm{~m}$ (and $200 \mathrm{~m}$ for Bannerman's Turaco) were excluded from the analysis owing to the difficulty in estimating longer distances. The maximum likelihood technique was used to limit the number of parameters chosen, and the Akaike Information Criterion (Buckland et al. 1993) was used to select the model that best fitted the data. Estimates were weighted by total stratum (vegetation type) sampling effort, where the sampling effort at a census station was the number of visits to the station. Densities were estimated by stratum, using a global detection function (the number of observations by stratum was too small in many cases). There were many species with insufficient records for density estimation. Therefore, for some statistical analyses, it was necessary to use relative abundance rather than density. In view of the variability of sampling effort among vegetation types, abundance was standardized to provide a comparable scale. For each census station the relative abundance of each species was the mean number of individuals recorded during all counts at the station. The relative abundance of each species in a given vegetation type was the average abundance over all census stations within the habitat. The habitat abundance data were subjected to the multivariate statistical technique of principal component analysis (PCA) on a correlation matrix to determine species that contributed most to variation among communities. The one-way analysis of variance technique was used to ascertain the existence of differences in the relative abundance of species between vegetation types. Census station data were treated as independent samples within each habitat.

The analytical framework presented above was used to assess the sensitivity of the monitoring programme to changes in bird densities. The assessment was carried out using a spreadsheet programme with the 1999-2000 data as the pilot data and $\propto=0.05$. Two inputs were calculated with DISTANCE, i.e. the slope of 
the probability density function of distances evaluated at zero for each habitat [h (o)] and the standard error [SE (h (o))]. Thus in the analysis, present refers to the pilot data and the only information about the next survey is the assumed sampling effort. However, because the analytical model requires constant sampling effort (as the standard errors of density from the pilot and next survey should be approximately equal) extrapolation of the model was restricted to not more than three times the sampling effort of the pilot survey (Table 1).

\section{Results}

A total of 89 species and 10,936 birds were recorded during 468 regular bird counts. Extending the counting duration to $15 \mathrm{~min}$ failed to improve the chances of detecting inconspicuous species, like Banded Wattle-Eye. Rather, there was a tendency to double count the same individuals.

Of the 89 species recorded during regular bird counts, densities were estimated for 17 species in some vegetation types. Reliable density estimation requires at least 40 observations (Buckland et al. 1993), but the majority of species were observed at much lower frequencies. In general, densities could only be estimated for species with more than 100 records when combined across vegetation types. The calculated densities are presented in the Appendix.

Considering all species recorded (92, including three recorded outside regular bird counts), $25.0 \%$ occurred in all vegetation types, $15.2 \%$ were restricted to degraded habitats (types 4 and 6), $13.0 \%$ to montane forest habitats (types 1-3 and 5 ) and $3.3 \%$ to the grasslands ( 7 and 8) (Table 2). Clearly, there was a high degree of overlap in the bird communities as measured by the Czekanowski similarity index (Bibby et al. 1998; Table 3). The greatest overlap was recorded between the forest habitats and the smallest was between forest and grassland. The difference between forest and grassland suggested a tendency for distinct bird communities in the Kilum-Ijim forest. The first two principal components (PC1 and $\mathrm{PC}_{2}$ ) of the PCA explained $51.3 \%$ of the variance among communities, essentially confirming the existence of distinct bird communities within the forest (Figure 2), i.e. birds of montane forests, degraded habitats and grasslands. PC1 explained $32.7 \%$ of the total variation, giving high positive weights (> 0.17) to forest birds like Grey-throated Greenbul Andropadus tephrolaemus and African Hill Babbler Pseudoalcippe abyssinica (Table 4). PC I further gave highly negative weights $(<-0.17)$ to grassland species, like Orange-tufted Sunbird Cinnyris bouvieri, Pectoral-patch Cisticola Cisticola brunnescens and Yellow Bishop Euplectes capensis. Clearly, PC1 separated forest communities from grasslands.

PC2 explained $18.6 \%$ of the total variation, giving high weights $(>0.17$ or $<-0.17)$ mostly to omnivores and insectivores such as African Thrush Turdus pelios, Brown-crowned Tchagra Tchagra australis and Black-headed Batis Batis minor. Lower weights were given to frugivores (e.g. Oriole Finch Linurgus olivaceus) and nectivores (e.g. Orange-tufted Sunbird). Thus PC2 appeared to separate species by their feeding guilds.

In view of the fact that many species were recorded at too low frequencies for reliable density estimation, relative abundance was used to ascertain the existence of differences between vegetation types. Sixty-seven bird species were subjected to the one-way analysis of variance test. Significant pairwise differences 
Table 2. Birds recorded in unique habitats.

\begin{tabular}{ll}
\hline Habitat & Bird species \\
\hline Montane & Cassin's Hawk Eagle Spizaetus africanus \\
& African Cuckoo Cuculus gularis \\
& Bar-tailed Trogon Apaloderma vittatum \\
White-headed Wood Hoopoe Phoeniculus bollei & Double-toothed Barbet Lybius bidentatus \\
& Grey-headed Woodpecker Dendropicos goertae \\
& Mountain Wagtail Motacilla clara \\
& Nightingale Luscinia megarhynchos \\
& Black-winged Oriole Oriolus nigripennis \\
& Mackinnon's Shrike Lanius mackinnoni \\
& Fülleborn's Boubou Laniarius poensis \\
& Splendid Glossy Starling Lamprotornis splendidus \\
& Blue-spotted Wood Dove Turtur afer \\
& Red-eyed Dove Streptopelia semitorquata \\
Green Turaco Tauraco persa \\
Blue-headed Coucal Centropus monachus \\
Yellow-spotted Barbet Buccanodon duchaillui \\
Tullberg's Woodpecker Campethera tullbergi \\
Cameroon Olive Greenbul Phyllastrephus poensis \\
Mocking Cliff Chat Myrmecocichla cinnamomeiventris \\
Blackcap Sylvia atricapilla \\
Splendid Sunbird Cinnyris coccinigastra \\
Brown-crowned Tchagra Tchagra australis \\
Waller's Chestnut-winged Starling Onychognathus walleri \\
Yellow-billed Oxpecker Buphagus africanus \\
Little Oliveback Nesocharis shelleyi \\
Tree Pipit Anthus trivialis \\
Snowy-crowned Robin-Chat Cossypha niveicapilla \\
Stout Cisticola Cisticola robustus \\
\hline
\end{tabular}

Table 3. Czekanowski similarity indices of the Kilum-Ijim bird communities.

\begin{tabular}{llllllll}
\hline Vegetation type & \multicolumn{7}{c}{ Vegetation type } \\
\cline { 2 - 8 } & 2 & 3 & 5 & 4 & 6 & 7 & 8 \\
\hline 1 & 0.865 & 0.804 & 0.712 & 0.830 & 0.800 & 0.649 & 0.632 \\
2 & & 0.857 & 0.733 & 0.821 & 0.808 & 0.682 & 0.659 \\
3 & & & 0.805 & 0.748 & 0.806 & 0.644 & 0.668 \\
5 & & & & 0.639 & 0.726 & 0.614 & 0.701 \\
4 & & & & & 0.790 & 0.685 & 0.564 \\
6 & & & & & & 0.733 & 0.686 \\
7 & & & & & & & 0.642 \\
\hline
\end{tabular}

were detected using the Tukey test. Of the 67 species tested, 16 showed significant differences in relative abundance between vegetation types $(P<0.05)$. Pectoral-patch Cisticola and Yellow Bishop were significantly more abundant in grasslands below 2,800 $\mathrm{m}$ than elsewhere in the forest while Green Longtail Urolais epichlora was more abundant in the lower montane forest than elsewhere. Other species tended to show significant differences in abundance between two 


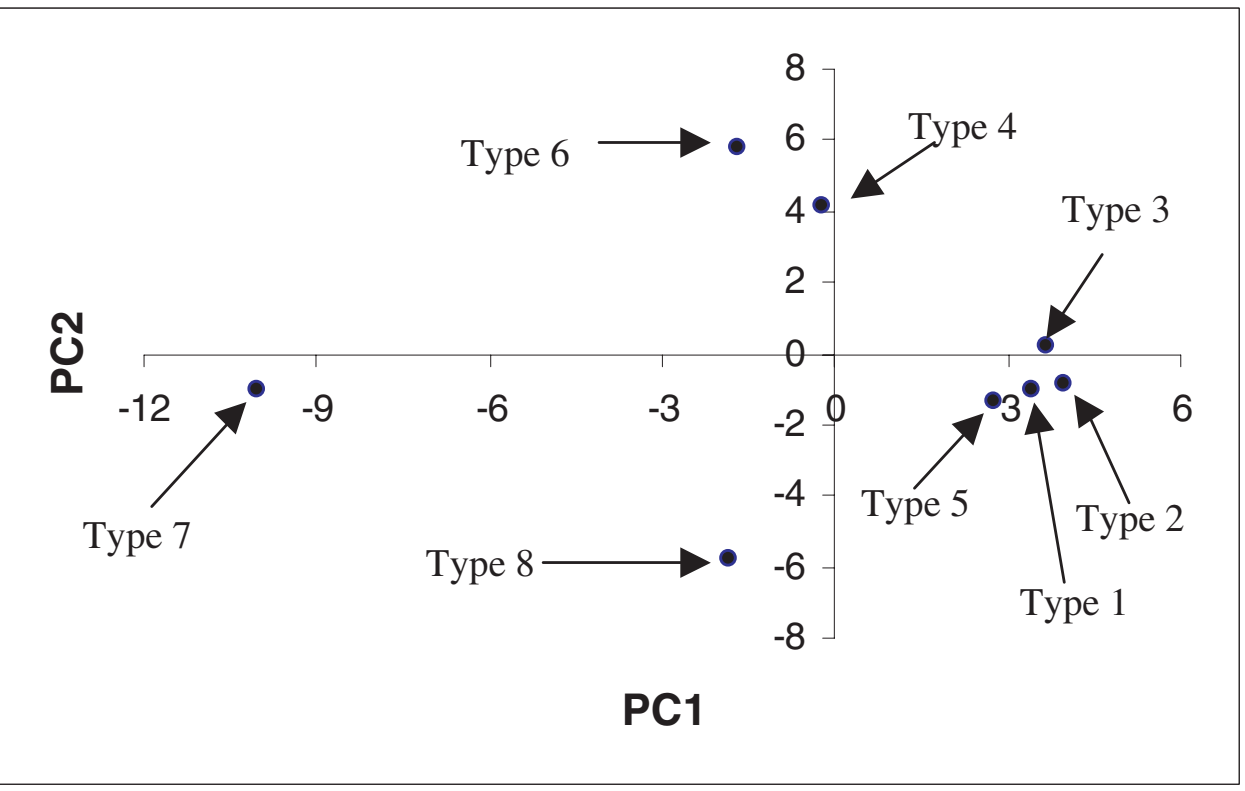

Figure 2. First two axes of the PCA ordination of bird communities within the Kilum-Ijim forest. Only species recorded in two or more habitats were considered.

or more vegetation types and thus were ranked by habitat preference on the basis of mean abundance (Table 5).

To answer how small a change in density could be detected by the monitoring scheme with a given sampling effort. two species were addressed, Bannerman's Turaco, with a moderate encounter rate, and Black-collared Apalis Apalis pulchra, which was common. The range of effort required to detect a stipulated change in density of both species should mirror the effort required to monitor other Kilum-Ijim species. The sampling effort of the pilot survey ranged from 50 surveys (vegetation type 1) to 84 (vegetation type 5) in the forest habitats. Clearly, the larger the sampling effort, the smaller the change that could be detected, but the incremental gains in detectable change diminished with increases in sampling effort (Figures 3 and 4 ). Moreover, sampling effort was habitat specific, except when abundance and detectability were approximately equal in the habitats in question. Except where sampling effort was large, the detectable change was species-specific (Figures 3 and 4 ).

\section{Discussion}

\section{Species list}

The 89 bird species recorded in 1999-2000 did not include all species on the Kilum-Ijim forest bird list. Dowsett-Lemaire and Dowsett (1998) listed 169 bird species for the forest, many of which were rare, inconspicuous and were missed during our surveys. Extending the counting duration to $15 \mathrm{~min}$ led to detection of the locally rare Little Greenbul Andropadus virens. However, considering all 
P.F. Forboseh et al.

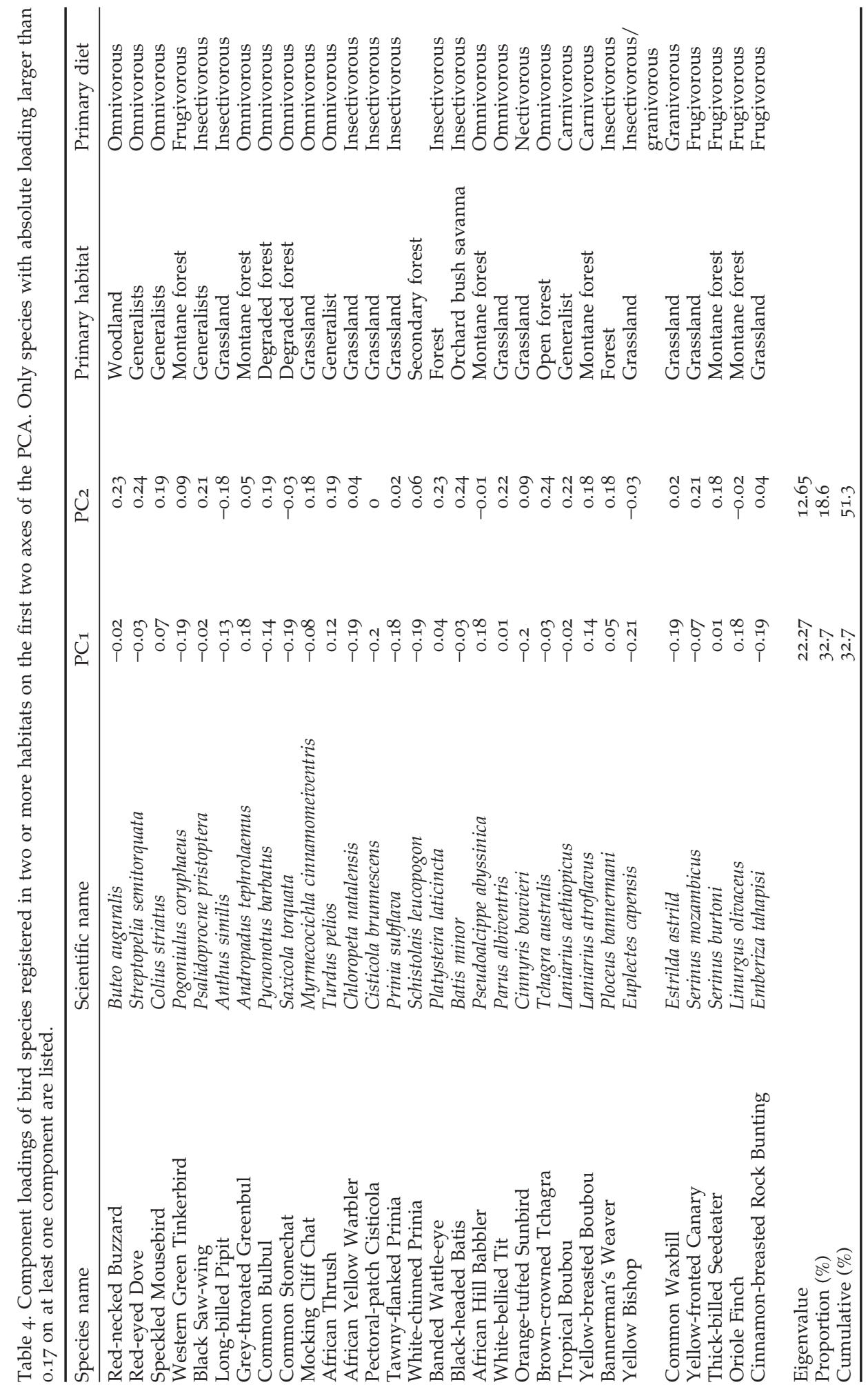


Table 5. Habitat preferences of Kilum-Ijim birds.

\begin{tabular}{llll}
\hline English name & Scientific name & $\begin{array}{l}\text { Preferred } \\
\text { vegetation } \\
\text { type }\end{array}$ & Habitat description \\
\hline Scaly Francolin & Francolinus squamatus & $1,6,2$ & Generalist \\
Bannerman's Turaco & Tauraco bannermani & $5,3,4$ & Generalist \\
Common Bulbul & Pycnonotus barbatus & $6,4,7$ & Woodland and grassland \\
Grey-throated Greenbul & Andropadus tephrolaemus & $3,2,1$ & Montane forest \\
Common Stonechat & Saxicola torquata & $7,4,8$ & Woodland and Grassland \\
Bangwa Forest Warbler & Bradypterus bangwaensis & $1,6,4$ & Generalist \\
Pectoral-patch Cisticola & Cisticola brunnescens & 7 & Grassland below 2,80o m \\
Green Longtail & Urolais epichlora & 3 & Lower montane forest \\
Black-collared Apalis & Apalis pulchra & $1,2,3$ & Montane forest \\
Grey Apalis & Apalis cinerea & $5,1,3$ & Montane forest \\
African Dusky Flycatcher & Muscicapa adusta & $2,5,4$ & Generalist \\
African Hill Babbler & Pseudoalcippe abyssinica & $1,3,2$ & Montane forest \\
Cameroon Blue-headed Sunbird & Cyanomitra oritis & $2,1,3$ & Montane forest \\
Yellow Bishop & Euplectes capensis & 7 & Grassland below 2,800 m \\
Red-faced Crimsonwing & Cryptospiza reichenovii & $4,3,1$ & Generalist \\
Oriole Finch & Linurgus olivaceus & $1,2,5$ & Montane forest \\
\hline & & & \\
\hline
\end{tabular}

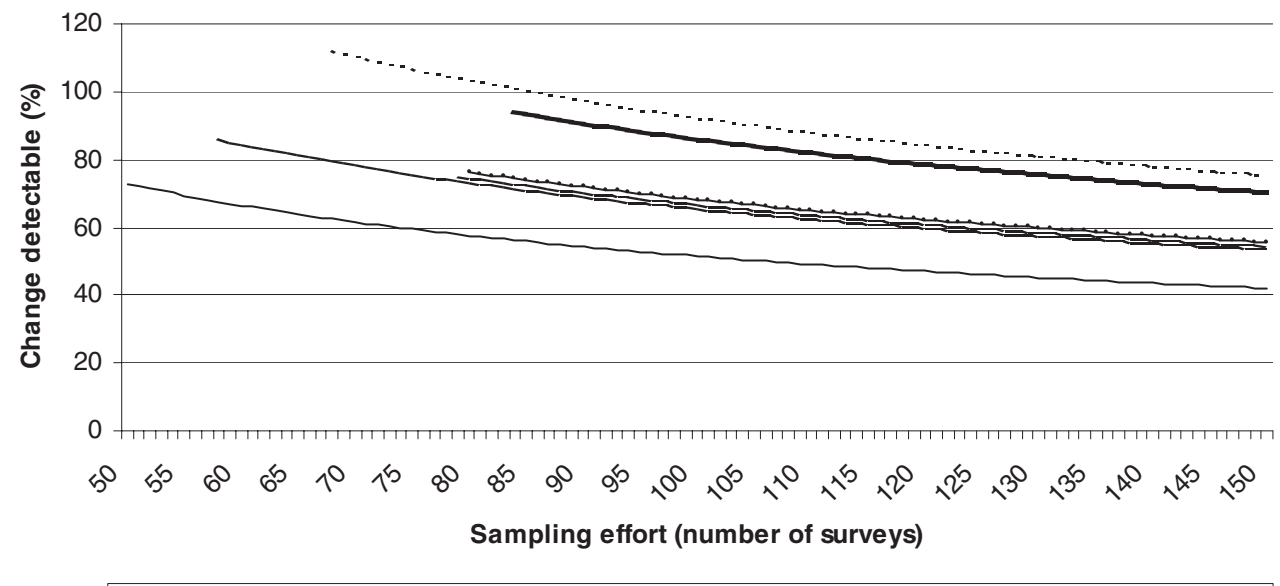

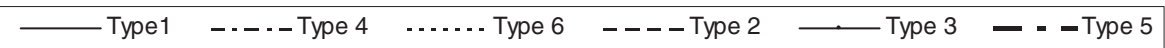

Figure 3. Sensitivity of the point transects method to changes in Bannerman's Turaco density at a range of sampling effort levels. (Types 2-4 require approximately the same sampling effort at a given level of sensitivity).

species in the current bird list, it appears highly unlikely that simply increasing the duration of bird counts would lead to a substantial increase in the number of species detected. Rather, detecting the inconspicuous species will require some targeted surveys.

\section{Bird densities}

Of the 89 bird species recorded at Kilum-Ijim in 1999-2002, densities could only be estimated for 17 species. Results for Bannerman's Turaco in the lower montane 

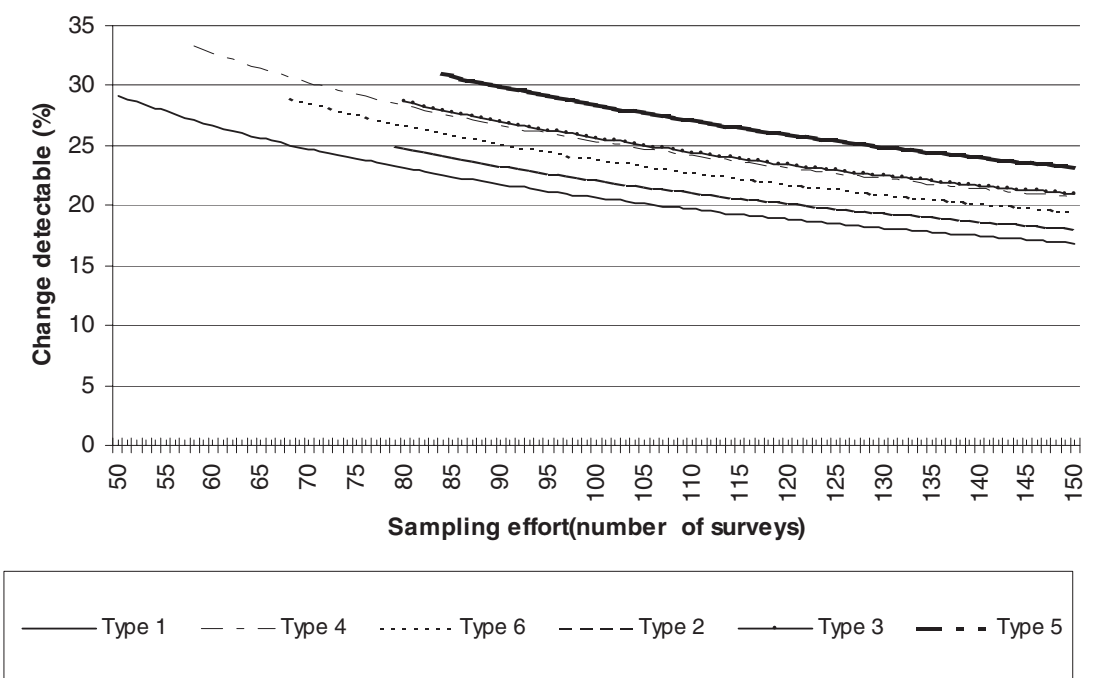

Figure 4. Sensitivity of the point transects method to changes in Black-collared Apalis density at a range of sampling effort levels.

forest (0.16 birds/ha, with 95\% confidence interval (CI) 0.09-0.28) appeared consistent with previous estimates of 0.26 (95\% CI 0.05-1.4) birds/ha (Forboseh and Ikfuingei 2001). Likewise, current results for the upper montane forest (0.12 birds/ha, with 95\% CI o.09-0.20) were consistent with previous estimates of 0.17 (95\% CI 0.13-0.22) birds/ha (Forboseh and Ikfuingei 2001). Fotso and Parrot (1991) reported lower estimates (0.08-0.12 pairs/ha), but their results were the average across multiple vegetation types. These results suggest stability in the density of Bannerman's Turaco at Kilum-Ijim since 1991. The paucity of quantitative literature on montane forest birds renders comparison of Kilum-Ijim results with those from similar sites impossible.

The measure of abundance implicit in the design of the Kilum-Ijim birdmonitoring programme is density, which is an absolute measure of abundance, and the central issue is the ability to detect changes in densities. However, the majority of the forest bird species were so rare that the total number of birds recorded by species during the 1999-2000 survey was very small, thus precluding reliable density estimation, except for the commonest species. Moreover, analyses using current rates of sampling effort suggested a low power for the system to detect real changes in density. Current results suggested that stipulating a $20 \%$ detectable change in bird densities with 95\% probability would entail at least a threefold increase in sampling effort for most vegetation types - a level of sampling that is clearly not attainable given existing resource constraints. Birdmonitoring currently consumes some $50 \%$ of the ecological monitoring resources. This leaves about $50 \%$ of the resources for monitoring other taxa. Moreover, a large increment in sampling effort is required for a relatively small gain in the power to detect real change, which increases in a non-linear manner with increases in sampling effort. 
The bird-monitoring programme could be optimized in ways that resource constraints are not seriously violated. Presently bird census stations are located considerable distances apart, so that monitoring teams make many day trips during which only one station is surveyed. If current census stations become the foci of a cluster of points that are sufficiently far apart and away from the edge of their vegetation types, it would be possible to at least double, or triple, the current survey effort without seriously violating the resource constraint. Tripling the current survey effort as suggested should allow detection of a $20-40 \%$ density change of many species in most habitats. Furthermore, the programme could combine species into ecological guilds (feeding, nesting or degree of forest dependence) as suggested by the PCA. Combining species in this manner could overcome the problem of low individual populations thereby increasing the power to detect real changes and provide an overall picture of how the value of the forest for birds is changing (Bennun and Fanshawe 1997). Additionally, the programme could concentrate all bird monitoring effort in habitats that are clearly shown to hold the best indicator species and/or use relative abundance, which requires less effort in sampling than density.

\section{Birds as indicators of vegetation condition and biodiversity}

Tropical forest birds often show narrow habitat preferences (Schemske and Brokaw 1981, after Ngabo and Dranzoa 2001; Bennun 2000). Therefore, we expected differential use of habitats by some species. A quarter $(25.0 \%)$ of species recorded during the surveys occurred in all vegetation types, showing that many Kilum-Ijim forest birds may have adapted to a wide range of habitat degradation. Indeed, experience from East Africa suggests that few primary forest birds become completely lost from forests that have been selectively logged (Bennun and Fanshawe 1997). However, our surveys missed a large number of species on Dowsett-Lemaire and Dowsett's (1998) bird list, many of which are likely to be habitat specialists that could suffer from habitat degradation. In all, $15.2 \%$ of the species recorded were restricted to the degraded habitats, $13.0 \%$ to the montane forest habitats and $3.3 \%$ to the grasslands. The PCA clearly separated the communities in the broad categories of relatively undisturbed forest birds, degraded forest birds and grassland birds. Moreover, PCA seemingly separated the birds by feeding guild, thereby suggesting that the bird communities exploit different food resources in their respective habitats. The PCA and analysis of variance results suggest the possibility of suites of bird species as indicators of the KilumIjim forest habitats.

The utility of bird species or a group of species as a habitat indicator depends on a thorough understanding of their responses to modifications in habitat. Little is known about the responses of Kilum-Ijim birds to habitat modification, and what may be known about them elsewhere may not necessarily apply to the Kilum-Ijim forest as bird species tend not to be always consistent in their ecology and behaviour over their entire range (Bennun and Fanshawe 1997). Thus if Kilum-Ijim forest birds must be used as indicators of habitat condition, it would be imperative to investigate their responses to habitat modifications (Bennun and Fanshawe 1997, Forboseh and Ikfuingei 2001). Should the investigation reveal 
species that show clear increases or decreases in abundance with specific habitat modifications, those species can be used as indicators of the particular habitat. The identification of birds that respond in a predictable manner to specific habitat modifications demands huge investment in effort and time. Natural fluctuations in populations dictate the need for a long baseline (Bennun 2000, 2001, Owino et al. 2002), without which it will be impossible to identify trends with a satisfactory degree of confidence. If the objective of the monitoring programme remains that of assessing changes in vegetation, then the objective could be more satisfactorily pursued through direct measurement of structural changes in the habitats (Morrison 1986) using permanent sampling plots as is already being done (Maisels and Forboseh 1997, Forboseh and Maisels 2000). In this case, the objective of the bird-monitoring programme could shift to assessing changes in the bird community. Detected changes in bird community would give an idea of the impact that directly measured vegetation changes are having on bird diversity. However, relating changes in bird diversity to overall forest biodiversity would necessitate a study of the relationship between the two (i.e. changes in the diversity of other organisms as a function of changes in bird populations or diversity), since little is known about this relationship at Kilum-Ijim.

There is intrinsic value in monitoring the population sizes of particular endemic and threatened bird species for their own status, especially if data on their ecological requirements were to be collected. Although the monitoring programme explicitly recognizes the utility of a better understanding of the ecological requirements of endemic birds, much less effort has gone into collecting the required data, compared with the effort that has gone into density estimation. A better understanding of the ecological requirements of endemic and threatened birds would provide the rationale for managerial interventions in the event of a real change in their densities. The bird-monitoring programme would be more productive if there were to be greater emphasis on the endemic and threatened species. Clearly, dealing with the suggested shifts in focus of the bird-monitoring programme will require changes beyond the optimization discussed above.

\section{Acknowledgements}

The Kilum-Ijim Forest Project is a joint programme of BirdLife International and the Ministry of Environment and Forestry of Cameroon (MINEF). The project is currently funded by the Global Environment Facility (GEF-UNDP) with matching funds from the British Department for International Development (DFID). All the other staff of the Kilum-Ijim Forest Project helped enormously, in logistics, helpful discussions, and, by their good team spirit and friendship, kept up morale for all concerned. Thank you! 


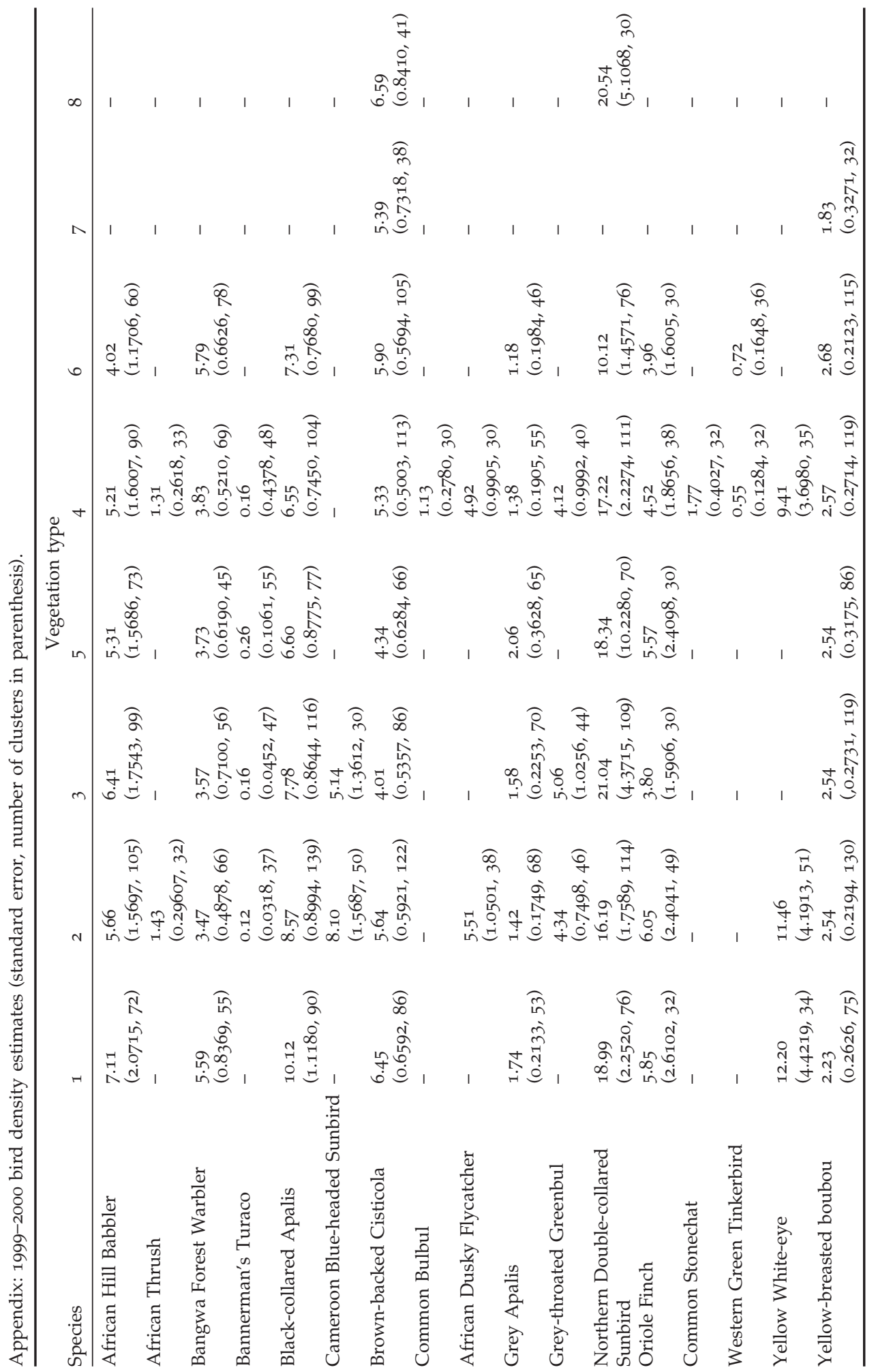




\section{References}

Bennun, L. A. (2002) Monitoring Important Bird Areas in Africa: a regional framework. Cambridge, U.K.: BirdLife International.

Bennun, L. A. (2001) Long-term monitoring and the conservation of tropical wetlands: high ideals and harsh realities. Hydrobiologia 458: 9-19.

Bennun, L. (2000) Assessing and monitoring bird populations in Africa: an overview. Ostrich 71 ( 1 and 2): 214--215.

Bennun, L. and Fanshawe, J. (1997) Using forest birds to evaluate forest management: an East African perspective. Pp. 10-22 in S. Doolan, S., ed. African rainforests and conservation of biodiversity. Oxford: Earthwatch Europe.

Bibby, C. J., Burgess, N. D. and Hill, D. A. (1992) Bird census techniques. BTO/RSPB. London: Academic Press.

Bibby, C. J., Jines, M. and Marsden, S. (1998) Expedition field techniques. bird surveys. London: Expedition Advisory Centre.

BirdLife International (2000) Threatened birds of the world. Barcelona and Cambridge, U.K.: Lynx Edicions and BirdLife International.

Buckland, S. T., Anderson, D. R., Burnham, K. P. and Laake, J. L. (1993) Distance sampling: estimating abundance of biological populations. London: Chapman and Hall.

Cheek, M., Onana, J-M. and Pollard, B. J., eds. (2000) The plants of Mount Oku and the Ijim Ridge, Cameroon. A conservation checklist. Kew: Royal Botanic Garden.

Collar, N. J., Crosby, M. J. and Statterfsfield A. J. (1994) Birds to watch 2: the world list of threatened birds. Cambridge, U.K.: Birdlife International (BirdLife Conservation Series 4).

Dowsett-Lemaire, F. and Dowsett, R.J. (1998) Surveys of Oku Mountain and other IBAs in NW Province, (Cameroon), February-March 1998. Report for BirdLife International. Tauraco a.s.b.l., Liège, Belgium.

ENGREF (1987) Massif d'Oku, Cameroon. Classement en reserve et principes pour un plan directeur d'amenagement. Summary. ENGREF- Centre Universitaire de Dschang.

Fishpool, L. D. C. (1997) Important Bird Areas in Africa. IBA criteria: categories, species lists and population thresholds. Cambridge, U.K.: BirdLife International.

Forboseh, P.F. and Ikfuingei, R. N. (2001) Estimating the population densities of Tauraco bannermani in the Kilum-Ijim forest, northwestern Cameroon. Ostrich Suppl. 15: 114118 .

Forboseh, P. and Maisels, F. (2000) The Kilum-Ijim forest vegetation survey 1999/2000: Ecological Monitoring Programme. KIFP, BirdLife International/ MINEF, Cameroon.

Fotso, R. C. and Parrot, J. R. (1991) Ecology and breeding biology of Bannerman's Turaco Tauraco bannermani. Bird Conserv. Internatnl. 1: 171-177

Laake, J. L., Buckland, S. T., Anderson, D. R. and Burnham, K. P. (1993) DISTANCE user's guide. Fort Collins, CO: Colorado Co-operative Fish and Wildlife Research Unit, Colorado State University.

Letouzey, R. (1985) Notice de la carte phytogeographique du Cameroun au 1: 500 ooo; Region Afro-montagnarde et étage submontagnard. IRA Yaoundé, Cameroun/Institut de la Carte Internationale de la vegetation, Toulouse, France.

Maisels, F. and Forboseh, P. F. (1997) The Kilum-Ijim forest vegetation survey: ecological Monitoring Programme. KIFP, BirdLife International/MINEF, Cameroon.

Morrison, M. L. (1986) Bird populations as indicators of environmental change. Curr. Orn. 3: 429-451.

Ngabo, C. K. M. and Dranzoa, C. (2001) Bird communities in gaps of Budongo Forest Reserve, Uganda. Ostrich Suppl. 15: 38-43.

Owino, A., Bennun, L., Nasirwa, O. and Oyugi J. (2002) Trends in waterbird numbers in the Southern Rift Valley of Kenya, 1991-2000. Waterbirds 25(2): 191-201

Schemske, D. W. and Brokaw, N. (1981) Treefalls and the distribution of understorey birds in a tropical forest. Ecol. Soc. America 62: 938-945. 
Stattersfield, A. J., Crosby, M. J., Long, A. J. and Wege, D. C. (1998) Endemic bird areas of the world: priorities for bird conservation. Cambridge, U.K.: BirdLife International (BirdLife Conservation Series 7).

Tame, S. and Asonganyi, J. (1995) Vegetation survey of the Ijim mountain forests, Northwest Province, Cameroon. Report, BirdLife International/GEF (World Bank)/MINEF.

Thomas, D. W. (1987) Vegetation of Mount Oku. Pp. 54-56 in H. Macleod Conservation of Oku Mountain Forest, Cameroon. Cambridge, U.K.: ICBP (Report 15).

Thomas, D. W. (1986) Vegetation in the montane forest of Cameroon. Pp. 20-27 in S.N. Stuart, ed. The conservation of the montane forests of Western Cameroon. Report of the ICBP Cameroon Montane Forest Survey.

Walsh, P. D. and White, L. J. T. (1999) What will it take to monitor forest elephant populations? Conserv. Biol. 13: 1194-1202.

PHILIP F. FORBOSEH, ERNEST C. KEMING, CLEMENT L. TOH and INNOCENT N. B. WUTOF

Kilum-Ijim Forest Project, PO Box 275, Bamenda, Cameroon. Email: forboseh@yahoo.com

Received 20 February 2002; revision accepted 14 April 2003 
